Blamberger

Versuch über

den deutschen Gegenwartsroman 
GÜNTER BLAMBERGER

\section{Versuch über den deutschen Gegenwartsroman}

Krisenbewußtsein und Neubegründung im Zeichen der Melancholie 
CIP-Kurztitelaufnahme der Deutschen Bibliothek

Blamberger, Günter:

Versuch über den deutschen Gegenwartsroman:

Krisenbewußtsein u. Neubegründung

im Zeichen d. Melancholie

Günter Blamberger.

- Stuttgart: Metzler, 1985

ISBN 978-3-476-00584-7

ISBN 978-3-476-00584-7

ISBN 978-3-476-03216-4 (eBook)

DOI $10.1007 / 978-3-476-03216-4$

(C) 1985 Springer-Verlag GmbH Deutschland

Ursprünglich erschienen bei J.B. Metzlersche Verlagsbuchhandlung und Carl Ernst Poeschel Verlag GmbH in Stuttgart 1985 


\section{INHALT}

\section{Vorwort 7}

\section{Erster Hauptteil}

Historisch-systematischer Versuch über den Zusammenhang von Melancholie- und Romantheorie

\section{Der Melancholiebegriff im »Zeitalter des Epos»}

1. Melancholie und homerisches Epos 11

2. Das aristotelische Melancholieproblem 13

3. Der Melancholiebegriff am Ausgang des Mittelalters oder Melancholie und "transzendentale Obdachlosigkeit« 16

II. Melancholie und Subjektivität. Zur Poetik des Romans

1. Der Melancholiebegriff in der Romantheorie von Georg Lukács 20

2. Anthropologischer Roman und Melancholie.

Ein Exkurs zur Genese des deutschen Romans nach Arbeiten von Hans-Jürgen Schings 24

3. Zur Krise des Romans in der Moderne:

Die Literaturtheorie Walter Benjamins 28

3.1. Einführung in den Gegenstand 28

3.2. Allegorie und Melancholie 30

3.3. Benjamins Erzähltheorie 37

3.4. Überlegungen zur Krise des Romans 44

III. Exkurs: Zeitkrankheit Melancholie - Psychoanalytische und soziologische Melancholieforschung im 20. Jahrhundert

Vorbemerkung 48

1. Melancholie aus der Sicht der Psychoanalyse und der analytischen

Sozialpsychologie 48

2. Beiträge der Soziologie zur Melancholieforschung 55 


\section{Zweiter Hauptteil}

Der deutsche Roman nach 1945 - Interpretationen

(Wolfgang Hildesheimer, Heinrich Böll, Günter Grass)

\section{Ausgangspositionen deutscher Literatur nach 1945}

II. Wolfgang Hildesheimers Prosa des Absurden

1. Lieblose Legenden (1952) 74

2. Hildesheimers Theorie einer Literatur des Absurden 77

3. Vergebliche Aufzeichnungen (1962) 81

4. Tynset (1965) und Masante (1973) 83

4.1. Die Beziehung von Autor und Ich-Erzähler 83

4.2. Die Welt als Labyrinth Gottes 86

4.3. "Die Zeit ist niemals in den Fugen gewesen " 90

4.4. "Niederschreiben um abzustreifen« oder Das Ende des Romans 96

III. Heinrich Bölls Poetik des Romans und die
"Ansichten eines Clowns" oder Literatur zwischen
Verzweiflung und Verantwortung

1. Der Melancholiebegriff in Ansichten eines Clowns (1963) 101

2. Über den Roman (1960) und Frankfurter Vorlesungen (1964) 104

3. Die Ansichten des Clowns Hans Schnier oder Melancholie und Gesellschaft 109

4. Bölls Mitleidslehre 116

5. Bölls Ästhetik des Humanen 125

6. Böll und der Roman der "klassischen Moderne« 130

IV. Anmerkungen zum Problem der Melancholie bei Günter Grass’ »Aus dem Tagebuch einer Schnecke» 135

Schlußwort 142

Anmerkungen 145

Siglenverzeichnis 189

Literaturverzeichnis 190

Namenregister 205 


\section{VORWORT}

Was in homerischer Zeit als Strafe der Hybris und in christlich-mittelalterlicher als Todsünde und teuflischer Zweifel am göttlichen Ordo gilt, ist für die Renaissancephilosophie in der Nachfolge des Aristoteles Voraussetzung der Genialität, der Ausweis des »deus in terris«. Was in der Aufklärung als irrationale und illegitime Kritik an der Möglichkeit eines vernünftigen Fortschritts zum irdischen Glück verurteilt werden kann und im orthodoxen Marxismus des 20. Jahrhunderts schlicht ein falsches Bewußtsein demonstriert, ist bei Adorno als würdige Verzweiflung die einzig noch angemessene Haltung angesichts der Insuffizienz menschlicher Ratio. Die Rede ist von der Melancholie.

Deren »berühmteste" Gestalt im Roman des 20. Jahrhunderts ist zweifelsohne Adrian Leverkühn. Die Spannung zum Absoluten verleiht seiner Melancholie traditionsgemäß die Größe und Thomas Manns Faustbuch den literarischen Rang. Leverkühns Nachfolger im Gegenwartsroman nehmen sich dagegen scheinbar medioker aus: Bölls Clown Hans Schnier oder Grass' authentisches Erzähler-Ich in Aus dem Tagebuch einer Schnek$k e$. Ihre Melancholie konstituiert sich allein aus den Problemen empirischer Realität. Sie ist keine metaphysische und erkenntnistheoretische Frage mehr, sondern nur noch eine geschichtliche und ethische. Sie hat nichts mehr gemein mit der abendländischen Tradition aristokratischer Melancholie, mit dem Leiden des "deus in terris « an der Inkludenz der Subjektivität, an der Vergeblichkeit des Griffs nach dem Absoluten.

Dem Wandel des Melancholiebegriffs entspricht einer der Romanpoetik. Thomas Manns Doktor Faustus ist noch ein Ausdruck der vergeblichen "Gesinnung zur Totalität ", die Lukács als konstitutiv für die Romanform beschreibt und aus deren Enttäuschung seiner Ansicht nach die "tiefe Melancholie" des Romanciers und seiner Helden resultiert. Die Krise des Romans in der Moderne spiegelt die Krise dieser Gesinnung wider. Von der Autorität der ästhetischen Theorie der Moderne und ihren Verdikten scheinen Böll und Grass dagegen frei. Subjektivität, Realismus und ethisches Engagement werden hier wieder zu Konstituentien der Romanpoetik. Ist dieser Wandel als pure Epigonalität zu werten, als »Rückfall « in die Poetik des realistischen Romans des 19. Jahrhunderts, oder einfach als Unterlaufen des erkenntnistheoretischen Anspruchs der Moderne, um dem »Tod des Romans" zu entgehen, den "Stillstand in der Krise « zu überwinden?

Die Unsicherheit der Forschung gegenüber dem Neuanfang des deut- 
schen Romans nach 1945 ist der kritische Ansatzpunkt der folgenden Untersuchung. Wir gehen von zwei Richtungen des Gegenwartsromans aus, denen unterschiedliche poetologische Modelle entsprechen. In der einen wird das Krisenbewußtsein der Moderne fortgeschrieben, in der anderen eine Neubegründung des Romans versucht.

Die vorliegende Arbeit gliedert sich in zwei Teile. Der erste besteht aus einem historisch-systematischen Versuch über den Zusammenhang von Melancholie- und Romantheorie, der den Bogen spannt vom homerischen Epos zum Roman der Moderne und sich dabei auf ausgewähltes Material aus der gut dokumentierten Geschichte des Melancholiebegriffs stützt. Er schließt u. a. kritische Analysen der Romantheorien von Lukács und Benjamin ein. Der zweite enthält Interpretationen zum deutschen Gegenwartsroman. Die theoretischen Ausgangspositionen der deutschen Literatur nach 1945 werden an der Programmatik des Ruf, dem publizistischen Vorläufer der "Gruppe 47 «, untersucht und dann die Paradigmen vorgestellt: Hildesheimers absurde Prosa für die Radikalisierung des Krisenbewußtseins der Moderne, Bölls Ansichten eines Clowns und Grass' Aus dem Tagebuch einer Schnecke für den Weg des Romans aus der Krise.

Die Untersuchung wurde im Frühjahr 1983 abgeschlossen. Sie wurde von der Friedrich-Naumann-Stiftung und der Deutschen Forschungs-Gemeinschaft gefördert. Dank schulde ich vor allem meinem Lehrer, Prof. Dr. Ulrich Fülleborn, der durch seine Überlegungen zum modernen Roman diese Studie anregte. Mein Dank gilt auch Dr. Andrea Pagni für die Korrektur der Arbeit. 